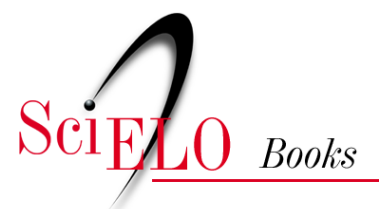

\title{
3. Literatura manuscrita nas leituras para a infância brasileira (1901-1955)
}

\author{
Estela Natalina Mantovani Bertoletti
}

\section{SciELO Books / SciELO Livros / SciELO Libros}

BERTOLETTI, E.N.M. Literatura manuscrita nas leituras para a infância brasileira (1901-1955). In: SILVA, M.C., and BERTOLETTI, E.N.M., orgs. Literatura, leitura e educação (online). Rio de Janeiro: EDUERJ, 2017, pp. 73-97. Pesquisa em educação/ Práticas de leitura e escrita series. ISBN 978-85-7511-497-1. Available from: doi: 10.7476/9788575114971.0004. Also available in ePUB from: http://books.scielo.org/id/5gg44/epub/silva-9788575114971.epub

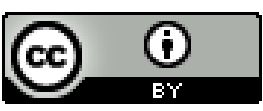

All the contents of this work, except where otherwise noted, is licensed under a Creative Commons Attribution 4.0 International license.

Todo o conteúdo deste trabalho, exceto quando houver ressalva, é publicado sob a licença Creative Commons Atribição $\underline{4.0}$.

Todo el contenido de esta obra, excepto donde se indique lo contrario, está bajo licencia de la licencia $\underline{\text { Creative Commons }}$ $\underline{\text { Reconocimento 4.0. }}$. 


\title{
3
}

\section{Literatura manuscrita nas leituras para a infância brasileira (1901-1955)}

\author{
Estela Natalina Mantovani Bertoletti
}

\section{Introduçáo}

O que se oferecia às crianças para leitura na escola brasileira quando esse se tornou um dos principais espaços sociais de educaçáo, na primeira metade do século XX?

Para responder a essa questão, é possível enumerar os textos e autores que circularam na escola a partir da análise dos livros de leitura que foram produzidos e aprovados para uso nesse espaço. Essa enumeração é considerada uma forma de acesso a um instrumento preliminar de pesquisa, que pode subsidiar e fornecer pistas que contribuam para a produção de uma história da leitura e do leitor, levando em conta os sujeitos e os objetos nela envolvidos.

Nesse sentido, buscando contribuir para a produção de pesquisas sobre livros escolares como fonte para a história da leitura e do leitor, o objetivo, aqui, é examinar o que se oferecia às crianças para leitura na escola brasileira, em um livro que circulou formando geraçôes de leitores: o livro de leitura manuscrita ou paleógrafo, Leitura manuscripta: liçôes colligidas, portador de uma literatura manuscrita para leitura na infância, nos limites da escola.

\footnotetext{
I. Este texto foi publicado na revista Teias, v. I6, n. 4I (20I5), e adequado para este livro.
} 
A escolha desse objeto de estudo deveu-se à sua singularidade: um livro impresso, porém em letra manuscrita, para o ensino da leitura de diversas grafias. Essa obra circulou na escola brasileira dentro do movimento de um incipiente mercado editorial, na primeira metade do século XX, concorrendo com outros paleógrafos e com outros livros de leitura impressos em letra bastáo. Além desse, outros foram os motivos:

I. Sua longevidade, tendo em vista que circulou por, pelo menos, 54 anos no mercado editorial brasileiro, com a primeira edição provavelmente em I90I, pela Tipografia Siqueira, ${ }^{2}$ passando, a partir da $9^{a}$ edição, em 1909, para a Livraria Francisco Alves e chegando à última edição em I955 (Razzini, 20I4);

2. O fato de seu circuito de produção e comunicação ter sido, entre os outros paleógrafos em circulação à época, o único totalmente brasileiro, com edição e impressão no país (Batista, 2009), pelas "Officinas Graphicas da Livraria Francisco Alves";

3. Sua inovação em relação aos outros paleógrafos que circulavam na escola brasileira, uma vez que, segundo Batista (2009, pp. $164-5)$,

[... a obra rompe com o modelo de organizaçáo bipartida dos paleógrafos anteriores, por conter apenas a antologia de textos, sem fazer a apresentaçáo prévia das letras do alfabeto em diferentes tipos de escrita. [...] apresenta a coletânea de textos, de diferentes autores, composta tanto de narrativas de fatos históricos ou de biografias (Bartolomeu Bueno da Silva, Bartolomeu Gusmão, os Andradas, a invenção da imprensa, entre outros) quanto de textos - e se trata de uma segunda ruptura promovida pela obra em relação às demais de uma literatura dirigida à leitura da criança na escola (adaptaçôes

2 Segundo Razzini (20I4), a Tipografia Siqueira teve várias denominações, sendo Typographia a vapor Espindola, Siqueira \& Comp. à época da publicação da primeira edição de Leitura $M a$ nuscripta. 
de fábulas, poemas, pequenas narrativas). A ocorrência, ainda, de autores de livros de instrução do final do século XIX entre as personagens biografadas é também um diferencial entre o livro e os demais paleógrafos [...].

Por tais motivos, realizei um exame dos textos e dos autores do livro Leitura manuscripta: liçóes colligidas, de modo a entender o que se dava para ler na escola brasileira na primeira metade do século XX, mediante os protocolos de leitura (Chartier, I990) autorizados que formaram geraçóes de leitores na escola, por mais de meio século.

\section{I Os livros de leitura na história da leitura e do leitor no Brasil}

Sabe-se que, no Brasil, pelo menos até meados do século XIX, raros eram os livros escolares para a infância. À época, circulavam uns poucos livros produzidos e publicados sobretudo na Europa, além de manuscritos, como documentos de cartório, cartas, textos religiosos, ofícios, entre outros, para o ensino da leitura (Pfromm Neto et al., I974). O depoimento de Sílvio Romero³ é elucidativo dessa afirmação:

Ainda alcancei o tempo em que nas aulas de primeiras letras apren-
dia-se a ler em velhos autos, velhas sentenças fornecidas pelos cartó-
rios dos escrivães forenses.
Histórias detestáveis e enfadonhas, em sua impertinente banalida-
de, eram-nos ministradas nesses poeirentos cartapácios. Eram como

3 Sílvio Vasconcelos da Silveira Ramos Romero nasceu em 2I de abril de I85I, em Lagarto/SE, e faleceu em I8 de julho de I9I4, no Rio de Janeiro/RJ. Foi crítico, ensaísta, folclorista, polemista, professor e historiador da literatura brasileira. Em 1897, fundou a cadeira no 17 da Academia Brasileira de Letras (ABL), escolhendo como patrono Hipólito da Costa (Academia, 20I7a, s.p.). 
clavas a nos esmagar o senso estético, embrutecer o raciocínio e estragar o caráter.

Era então precisa uma abundante seiva nativa para resistir a semelhante devastação (Romero apud Zilberman e Lajolo, I988, p. 265).

Do mesmo modo, a narração de João Lourenço Rodrigues, ${ }^{4}$ recuperada por Pfromm Neto et al. (I974), ilustra a questáo:

[...] o professor preparava um $\mathrm{ABC}$ manuscrito, em folha de papel, que se pegava "com pega-mão, para não sujar". Em seguida à carta manuscrita do $\mathrm{ABC}$, "veio o b-a-bá, que servia de início à série bastante longa das cartas das sílabas. Depois destas vieram as cartas de nomes e por último as cartas de fora, que serviam de remate à aprendizagem da leitura. O método adotado era o da soletração. As cartas de fora, cedidas ao professor por empréstimo, serviam para exercitar os alunos nas dificuldades da letra manuscrita (...). Os meninos tinham direito de escolha e davam preferência a certas dessas cartas, de formato maior e conteúdo menor. Eram ofícios dirigidos ao professor e alguns deles traziam a assinatura do Inspetor Geral” (Pfromm Neto et al., 1974, p. 159, grifos dos autores).

Nesse sentido, muitos eram os reclamos de intelectuais e educadores não somente quanto à falta de material especialmente produzido para esse fim, como também à falta de produto brasileiro, seja pelos temas, seja pela feitura de material, seja ainda pelos autores. Emblemático é o posicionamento de José Veríssimos

4 Joāo Lourenço Rodrigues era aluno da escola primária, em I875, segundo Pfromm Neto et. al. (1974).

5 José Veríssimo Dias de Matos nasceu em 8 de abril de 1857, em Óbidos/PA, e faleceu em 2 de fevereiro de 1916, no Rio de Janeiro/ RJ. Foi jornalista, professor, educador, crítico e historiador literário. Fundou a cadeira $\mathrm{n}^{\circ} \mathrm{I} 8 \mathrm{da} \mathrm{ABL}$, tendo sido eleito como patrono João Francisco Lisboa (Academia, 20I7b, s.p.). 
(I896) sobre essa situação, clamando por um livro de leitura para brasileiros.

Cumpre que ele seja brasileiro, não só feito por brasileiros, que não é o mais importante, mas brasileiro pelos assuntos, pelo espírito, pelos autores trasladados, pelos poetas reproduzidos e pelo sentimento nacional que o anime (Veríssimo apud Zilberman e Lajolo, I988, p. 272).

Como é possível observar por esses depoimentos, a natureza dos livros escolares é complexa, não somente por seu conteúdo, mas também por seu próprio formato e finalidade:

[...] os livros didáticos nem sempre são livros, mas apresentam-se em diferentes suportes materiais; o texto didático nem sempre se restringe ao texto explicitamente elaborado e reproduzido tendo em vista um destino escolar; tampouco o texto didático é uniforme na maneira como se articula com o trabalho de ensino e com a formação que pretende auxiliar [...] (Galvão e Batista, 2009, p. 28).

Já no século $\mathrm{XX}$, os materiais didáticos especialmente voltados para a infância brasileira passaram a ser não somente reivindicados, como também produzidos, incentivando o nascimento de um mercado especializado no que se convencionou chamar de livros escolares.

Bastante híbridos, complexos e fluidos em sua gênese, os livros escolares brasileiros oscilavam entre aqueles de caráter mais pedagógico e os outros de caráter mais ficcional e de fantasia, sempre voltados, contudo, à preocupação de levar ensinamento útil de forma agradável, de modo a substituir, paulatinamente, os "detestáveis e enfadonhos" materiais produzidos em outros países ou em 
outras esferas da sociedade, como os manuscritos mencionados, e utilizados na escola para o ensino da tríade: ler, escrever e contar.

Sobre os livros escolares de ficção, concebidos como "literatura infantil”, uma vez que eram produzidos intencionalmente para a criança leitora, Hansen (20II, p. 54), analisando-os em seus aspectos cívico-pedagógicos e nacionais, sobretudo aqueles que apresentam caráter de fantasia, afirma textualmente que, neles, estabelecia-se um campo "[...] de disputa entre diferentes projetos para o futuro da nação brasileira [...]”, uma vez que a criança era idealizada como futuro cidadão "[...] que, ao se tornar objeto de uma ação pedagógica eficaz, transformar-se-ia no principal agente do progresso do país" (Idem, p. 78).

Em relação à importância dos livros escolares no ensino, Soares (I996) assevera:

[...] o livro didático instituiu-se, historicamente, bem antes [do] estabelecimento de programas e currículos mínimos como instrumento para assegurar a aquisição de saberes escolares, isto é, daqueles saberes e competências julgados indispensáveis à inserção das novas geraçôes na sociedade, aqueles saberes que a ninguém é permitido ignorar (p. 55).

Nesse aspecto, entre os livros escolares produzidos, encontram-se cartilhas, livros de leitura, manuais de ensino, livros de literatura infantil, antologias, entre outros. Inicialmente produzidos por um tímido mercado editorial brasileiro, levando-se em conta o escasso público a que se dirigia, ${ }^{6}$ esses livros foram se espe-

6 De acordo com Pfromm Neto et al. (1974, p. I70), “em I836, não ia além de 640 o número de alunos das escolas primárias no município da Corte. De meados do século a I870, o total de alunos matriculados elevou-se de pouco mais de setenta mil para quase cento e noventa mil. Em I886, o país contava com 213.670 alunos matriculados em 6.605 escolas primárias públicas. Em algumas províncias - que, após o Ato Adicional de I834, passaram a legislar sobre 
cializando e sofisticando seus métodos, técnicas e alcance. Desse modo, os livros escolares tornaram-se um material indispensável no processo de escolarização das crianças até os dias atuais.

Nesse contexto, sob diferentes configuraçôes e projetos editoriais, os livros escolares brasileiros representaram diversos modos de se conceber a formação do leitor (Lajolo e Zilberman, I99I), em consonância com as exigências específicas da escola e de formação de e para a infância (Corrêa, 2000). Isso justifica a escolha de textos e autores que os compunham, bem como a estrutura e a forma que apresentavam, obedecendo a um projeto editorial em diálogo com as necessidades e os objetivos educacionais de sua época.

Os livros de leitura manuscrita, ou paleógrafos, destinavam-se ao ensino da leitura, e náo da escrita, e cumpriram uma espécie de transição entre os escassos materiais para ensino da leitura, elaborados pelos próprios professores, e os livros de leitura mais sofisticados e com um padrão estabelecido nas séries de leitura graduada. Nesse sentido, pode-se dizer que conviveram com essas séries, concorrendo e cumprindo objetivo diverso e de grande relevância social à época, no que diz respeito ao ensino da leitura de diferentes caligrafias que circulavam socialmente.

Batista (2005) organizou dados sobre sete paleógrafos que tiveram circulação, pelo menos de meados do século XIX a meados do século XX.

ensino público - cresceu significativamente o movimento em favor da escola elementar, na segunda metade do século passado". 
Quadro 3.I. Paleógrafos ou livros de leitura manuscrita

\begin{tabular}{|c|c|c|c|}
\hline Título & Autor & $\begin{array}{l}\text { I }^{\text {a }} \text { ediçáo } \\
\text { localizada }\end{array}$ & Circulaçáo \\
\hline $\begin{array}{l}\text { Arte de aprender a ler a letra ma- } \\
\text { nuscrita para uso das Escholas em } \\
\text { Io liçóes progressivas do mais fácil a } \\
\text { o mais difícil }\end{array}$ & $\begin{array}{l}\text { Duar- } \\
\text { te Ventura }\end{array}$ & $\begin{array}{l}\text { Provavelmen- } \\
\text { te em I } 840\end{array}$ & até I9OI \\
\hline $\begin{array}{l}\text { O paleographo em escala calligra- } \\
\text { phica para apprender a leitura ma- } \\
\text { nuscripta, approvado pelo Conselho } \\
\text { Superior d'Instrucçâo }\end{array}$ & Carlos Silva & I864 & até I9I2 \\
\hline $\begin{array}{l}\text { O segundo e novo paleographo, em } \\
\text { escala calligraphica: leitura manus- } \\
\text { cripta etc. }\end{array}$ & Carlos Silva & 1869 & $\begin{array}{l}\text { Não } \\
\text { informado }\end{array}$ \\
\hline $\begin{array}{l}\text { Paleographo, ou Arte de aprender } \\
\text { a ler a letra manuscripta, para uso } \\
\text { das escolas da Provincia do Pará }\end{array}$ & $\begin{array}{l}\text { Joaquim Pe- } \\
\text { dro Corrêa } \\
\text { de Freitas }\end{array}$ & I87I & $\mathrm{I} 3^{\mathrm{a}} \mathrm{em} \mathrm{I} 886$ \\
\hline $\begin{array}{l}\text { Curso graduado de letra manuscri- } \\
\text { ta em } 2 \text { I liçóes composto para o uso } \\
\text { da mocidade brasileira }\end{array}$ & $\begin{array}{l}\text { sem indicação } \\
\text { de autoria }\end{array}$ & $\begin{array}{l}\text { segunda } \\
\text { edição em I872 }\end{array}$ & nona em I890 \\
\hline Leitura Manuscripta & $\mathrm{BPR}$ & I9OI & 1955 \\
\hline Exercicio de leitura manuscrita & $\begin{array}{l}\text { Lin- } \\
\text { dolfo Gomes }\end{array}$ & 1926 & 1963 \\
\hline
\end{tabular}

Fonte: Batista, 2005.

Conforme se observa, no Brasil os livros de leitura manuscrita circularam por mais de cem anos e, entre eles, estava Leitura manuscripta. A primeira edição desse livro circulou ao lado de, pelo menos, dois outros paleógrafos: Arte de aprender a ler a letra manuscrita para uso das Escholas em Io liçöes progressivas do mais fácil a o mais dificil, de Duarte Ventura, e $O$ paleographo em escala calligraphica para apprender a leitura manuscripta, approvado pelo Conselho Superior d'Instrucção, de Carlos Silva. Além disso, manteve-se no mercado editorial, concorrendo náo somente com outro, Exercício de leitura manuscrita, de Lindolfo Gomes, como também com uma cultura que foi, aos poucos, colocando em segun- 
do plano a exigência social que provavelmente gerou a necessidade de publicar livros para o ensino da leitura de textos escritos em letra manuscrita: a de leitura de diferentes caligrafias.

Se, durante o século XIX, a leitura de manuscritos era uma urgência devido à grande circulação desse tipo de material em todas as esferas da sociedade, inclusive na escola, os paleógrafos supriam a necessidade de ensino da letra manuscrita, substituindo, de uma forma mais sofisticada, aquele tipo de documento. Em vista disso, a legislaçáo escolar previa o ensino de leitura manuscrita, e o mercado editorial de livros escolares buscou preencher e aproveitar essa fatia no mundo das ediçóes, como já se ressaltou. No século XX, entretanto, a exigência social de leitura manuscrita foi reduzida, de modo crescente, pela circulaçáo cada vez maior de impressos reproduzidos em diferentes técnicas e tipos de letra bastão. A longevidade de Leitura manuscripta é, portanto, um fenômeno digno de análise. ${ }^{7}$

\subsection{O livro Leitura manuscripta: liçóes colligidas}

\subsection{Aspectos editoriais}

O livro Leitura manuscripta: liçóes colligidas ${ }^{8}$ é composto de textos reproduzidos por processo litográfico em diferentes letras, todas verticais, e encadernado em brochura no formato in-I2. ${ }^{9}$ A capa dura contém a única ilustraçâo do livro: um galho sobre

\footnotetext{
7 É curioso notar que poucos são os estudos sobre eles, à exceção de mençôes à sua existência e, mais pontualmente, alguns esboços de sua trajetória e circuito de produção e comunicação (Darnton, 20I0). Em alguns casos, inclusive, há análises descritivas de sua materialidade, como em Batista (2005; 2009), o que aponta para lacunas e necessidades de pesquisa.

8 Năo conseguimos precisar a data de publicação do exemplar analisado, uma vez que não era comum essa informação em seus exemplares. Provavelmente, trata-se de uma ediçáa da década de I930, já que há uma inscrição de uso no verso da capa com a data de 1935 .

9 O formato in-I2 corresponde ao formato francês de I7,5cm x IIcm (Hallewell, 2005).
} 
o qual repousa um pássaro, ocupando toda a margem direita e o alto da folha. Traz também título, subtítulo e autoria indicada apenas pelas iniciais (BPR), todas em letras manuscritas e carimbo com indicação da editora e dos locais (Rio de Janeiro, São Paulo e Belo Horizonte). A quarta capa traz um extrato do catálogo da Livraria Francisco Alves, contendo título e preço de livros escolares, separados por autores. Uma lista dos livros de autoria de Arnaldo de Oliveira Barreto, Romão Puiggari, Thomaz Antonio Galhardo e Ramon Rocca Dordal ${ }^{10}$ antecede a folha de rosto, que reproduz as informaçôes da capa, sem ilustração.

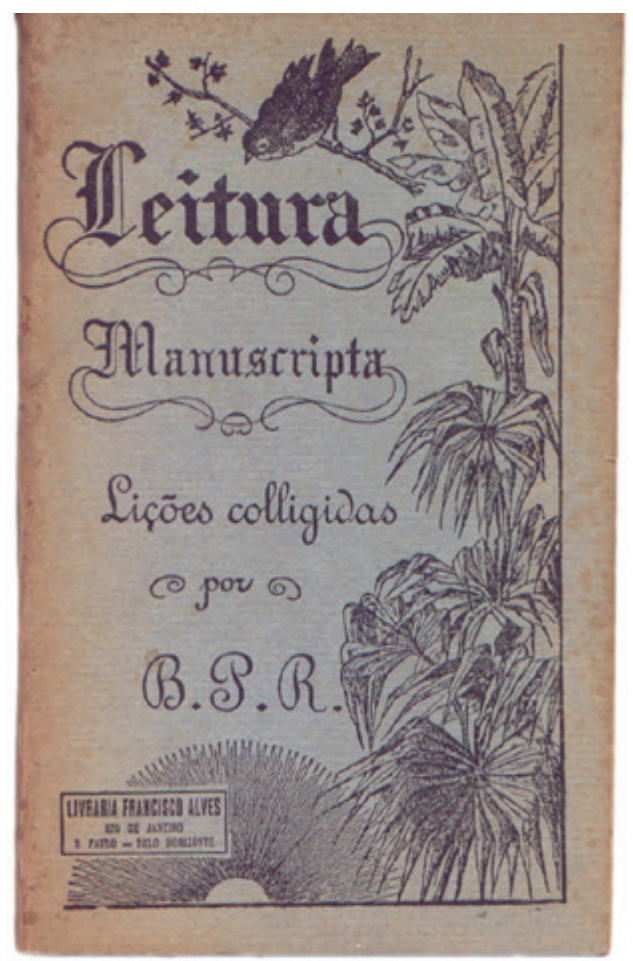

Figura I: Capa do livro Leitura Manuscripta - Liçóes colligidas

Fonte: Acervo particular de L.S.M.

Io Estudos sobre Arnaldo Barreto, Ramon Rocca e Thomaz Galhardo como sujeitos da história do ensino de leitura e escrita no Brasil podem ser vislumbrados, respectivamente, em: Bernardes (2015); Pasquim (2015); e Santos (2015). 
Antes dos textos que se iniciam na página 5 e seguem numerados até a p. I28, tem-se a informação "Approvado e adoptado pelo Governo para as Escolas publicas do Estado", o que significa que o livro não somente foi autorizado, como também foi comprado para ser distribuído às escolas, e que a longevidade de publicação de Leitura Manuscripta representou sua utilizaçáo efetiva para o ensino da leitura, se levarmos em conta que a compra leva à adoção do material.

Ao final de alguns textos, existem quadros pautados contendo ora letras do alfabeto, ora numerais, ora frases curtas, indicando uma possível utilização do livro também para o ensino da escrita, embora não fosse essa a funçâo primeira dos paleógrafos, conforme já assinalado.

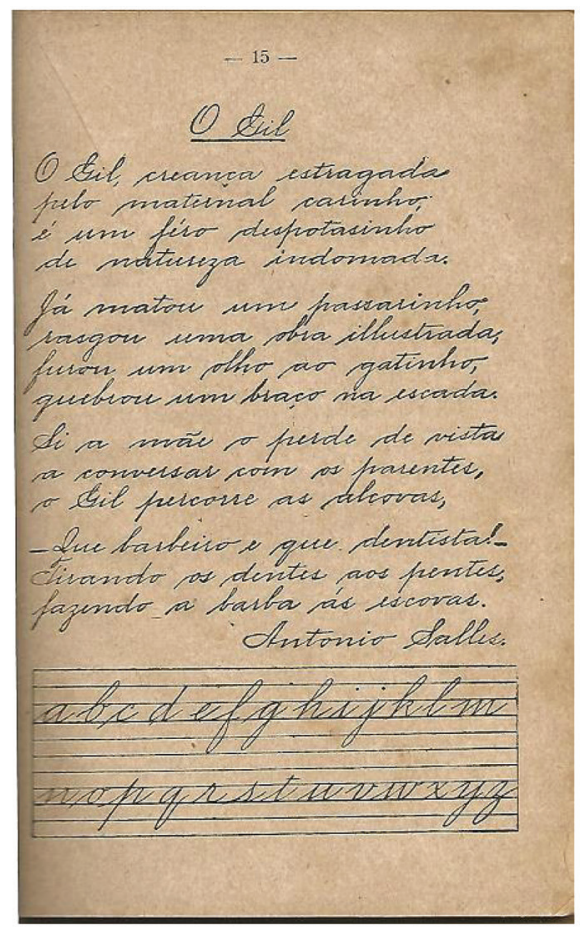

Figura 2: Quadro pautado ao final do texto "O Gil"

Fonte: Acervo particular de L.S.M. 
É curioso notar a autoria do livro indicada apenas pelas iniciais BPR. De acordo com Batista (2009), trata-se de Arnaldo de Oliveira Barreto, Romão Puiggari e Ramon Rocca. Razzini (20I4), contudo, afirma que o B corresponde a Alfredo Bresser. Seja Barreto ou Bresser, importa salientar e questionar por que professores e autores de livros didáticos como os apontados como autores de Leitura manuscripta omitiriam essa informaçáo. Teriam vendido os direitos autorais para a Livraria Francisco Alves? A estratégia de venda de livros a partir do renome do autor não teria sido considerada necessária pelo editor?

Pfromm Neto et al. (1974) ressaltam o desejo de elaborar livros de leitura e outros textos didáticos despertado em autores como os citados, quando surgiram condiçóes favoráveis para o estabelecimento e a ampliaçáo do mercado de livros escolares, a partir do crescimento do número de matrículas de alunos e de escolas primárias no Brasil.

Hallewell (2005), igualmente, destaca o interesse de editores nacionais propiciado pela melhoria da qualidade da educação, a ponto de criar um mercado viável para os livros escolares. Nesse sentido, é possível notar, no livro em questão, características do progresso nas técnicas de edição que sedimentaram paulatinamente os livros escolares no Brasil.

\subsubsection{Os textos}

O livro Leitura manuscripta: liçôes colligidas é organizado em 65 textos, organizados em forma de índice, conforme se vê a seguir.

Quadro 3.2 Textos e autores do livro Leitura manuscripta: liçōes colligidas

\begin{tabular}{ll} 
Título & Autor \\
\hline A Calligraphia & BPR \\
\hline A lingua portuguesa & José Bonifácio \\
\hline
\end{tabular}


Título

\begin{tabular}{|c|c|}
\hline Vozes de animaes & Pedro Diniz \\
\hline Lucas & Castro Alves \\
\hline O Gil & Antonio Salles \\
\hline Natal & Antonio Salles \\
\hline Anniversario & Alvares de Azevedo \\
\hline Arrependimento infantil & Mendes Leal \\
\hline Bosquejo & Raymundo Corrêa \\
\hline A superstição & Felisberto de Carvalho \\
\hline Felisberto de Carvalho & Sem indicação de autoria \\
\hline As duas mães & Bulhão Pato \\
\hline Amor de familia & Camilo Castello Branco \\
\hline A lagarta e o bicho da seda & Feliciano de Castilho \\
\hline Um castello... em papas! (autographo) & Arnaldo de Oliveira Barreto \\
\hline A Palavra & Latino Coelho \\
\hline Antonio Joäo & Escragnolle Taunay \\
\hline Amigos & Guilherme Braga \\
\hline O relógio (autographo) & Arnaldo de Oliveira Barreto \\
\hline Glorias futuras & Hilario Ribeiro \\
\hline Hilario Ribeiro & Sem indicação de autoria \\
\hline O leão e a raposa & Marqueza de Alorna \\
\hline Piratininga & Americo Brasiliense \\
\hline D. Maria de Souza & Manuel de Azevedo \\
\hline Chromo & B. Lopes \\
\hline O mestre de reza & M. A. d'Almeida \\
\hline Bartholomeu Bueno da Silva & Pinheiro Chaga \\
\hline O orgulho da águia & Vicente de Carvalho \\
\hline Astucia do tigre & Fr. Luis de Granado \\
\hline Patria (autographo) & Carlos Gomes Cardim \\
\hline O Sabiá & Fagundes Varella \\
\hline O lobo e o cordeiro & Pe. M. Bernardes \\
\hline A raposa e as uvas & Bocage \\
\hline Salto de Itú & Salvador de Mendonça \\
\hline Eia avante! & Rozendo Monis \\
\hline Opresbyterio & Alexandre Herculano \\
\hline O lobo e o cáo magro & Eduardo Garrido \\
\hline Caçada de bugio & A. Vieira \\
\hline Frei Fulgencio & D. M. Azevedo \\
\hline
\end{tabular}


Título

\begin{tabular}{ll}
\hline Oratinho (autographo) & Ramon Puiggari \\
\hline Rumo do Oriente (autographo) & Amadeu Amaral \\
\hline Um Raio de Sol & Suzanina Cornaz \\
\hline Mäe e Filho (autographo) & J. Pinto e Silva \\
\hline Um estratagema & Joáo Francisco Lisbôa \\
\hline O Padre voador & Sem indicaçáo de autoria \\
\hline Marinha (autographo) & Alberto Souza \\
\hline General Osorio & E. Osorio \\
\hline A primeira escola de S. Paulo & Compilaçóes históricas de R. \\
& Puiggari \\
\hline Um apólogo & Machado de Assis \\
\hline Um quináo & Joáo Borges \\
\hline Meus companheiros & Ramon Puiggari \\
\hline A volta (autographo) & J. Pinto e Silva \\
\hline Jaguarari & Gonçalves Dias \\
\hline Guttenberg e a imprensa & Barão de Macahubas \\
\hline Baräo de Macahubas & Sem indicaçáo de autoria \\
\hline Inteireza dos Andradas & Antonio Menezes Vasconcellos \\
& de Drummond \\
\hline O poeta Silva Alvarenga & Sem indicaçáo de autoria \\
\hline Um anjinho enfermeiro & Menezes Vieira \\
\hline Dr. Menezes Vieira & Sem indicaçáo de autoria \\
\hline A Flôr & A. Feliciano de Castilho \\
\hline O desembargador Petra & Joaquim Manoel de Macedo \\
\hline Joaquim Manoel de Macedo & Sem indicaçáo de autoria \\
\hline Maxima & Marquês de Maricá \\
\hline A cigarra e a formiga & Bocage \\
\hline O Brasil & Sebastião da Rocha Pitta \\
\hline
\end{tabular}

Fonte: Leitura manuscripta: liçōes colligidas.

Como se observa no Quadro 3.2, todos os textos são intitulados e foram produzidos por 52 diferentes autores, sendo que 58 desses textos vêm assinados. ${ }^{\text {II }}$ A grande quantidade de autores em relação ao número de textos justifica-se por se tratar de uma co-

II Apenas em sete textos não há indicação de autoria. 
letânea, como já ressaltado em relação ao subtítulo do livro, uma vez que foi esse o modelo de livro de leitura que prevaleceu no final do século XIX, no Brasil (Soares, 200I), sendo 34 autores brasileiros, I7 portugueses e um espanhol. A presença maciça de autores de nosso país representa uma resposta aos reclamos dos intelectuais daquele tempo, assinalada no início deste artigo.

O primeiro texto, assinado por BPR, trata, em forma de diálogo, da importância da caligrafia, embora nenhum desses autores (Arnaldo Barreto ou Alfredo Bresser, Romão Puiggari e Ramon Rocca) fosse calígrafo. Desse modo, o tema é abordado do ponto de vista da educaçáo, haja vista a atuaçáo desses autores como professores que propunham modos de fazer e de pensar a educaçáo brasileira, atuando, sobretudo, no ensino de leitura e de escrita.

[..] A calligraphia deve ser cuidada com carinho. Uma bonita lettra é um excelente dote no homem. Digo-te mais, é uma prova de boa educação.

- De boa educação, papae?

- Sim. A boa educação, a civilidade, eu a resumo em poucas palavras. Para mim não consiste em certas e determinadas etiquetas, mas num principio que as resume todas e que a todas deve servir de base. Este principio é o seguinte:

Em nossas relaçóes, tanto familiares como sociaes, devemos procurar sempre aquillo que fôr agradável ás pessoas com quem tratamos e evitar tudo aquillo que possa ser desagradável (BPR, s.d., pp. 6-7).

Ainda assim, são de próprio punho os textos de autoria de Arnaldo de Oliveira Barreto e Romáo Puiggari, bem como outros cinco deles, que foram reproduzidos no livro pelos próprios autores, na qualidade de autógrafos, como se verifica também no Qua- 
dro 3.I: Carlos Gomes Cardim, Amadeu Amaral, Alberto Sousa e J. Pinto e Silva. É importante ressaltar que os dois últimos são autores de textos que foram produzidos antes de 1900.

Além desses, a maioria dos autores é contemporânea à publicação do livro, sendo considerados clássicos, à época, somente sete deles, como Antonio Ferreira de Castilho, Bocage, Fr. Luís de Granada, Marquês de Maricá, Pe. Antonio Vieira, Pe. Manuel Bernardes e Rocha Pitta. Sobre a presença de autores antigos nos livros de leitura e a necessidade de haver autores brasileiros e "modernos", a crítica de José Veríssimo (I896) é, mais uma vez, significativa:

Os nossos livros de excertos é aos autores portugueses que os vão buscar, e a autores cuja clássica e hoje quase obsoleta linguagem o nosso mal amanhado preparatoriano de português mal percebe. São os Fr. Luís de Sousas, os Lucenas, os Bernardes, os Fernão Mendes e todo o classicismo português que lemos nas nossas classes da língua, que aliás começa a tomar nos programas o nome de língua nacional. Pois, se pretende, ao meu ver erradamente, começar o estudo da língua pelos clássicos, autores brasileiros, tratando as coisas brasileiras, não poderiam fornecer relevantes passagens? E Santa Rita Durão, e Caldas, e Basílio da Gama, e os poetas da gloriosa escola mineira, e entre os modernos João Lisboa, Gonçalves Dias, Sotero dos Reis, Machado de Assis e Franklin Távora, e ainda outros, não têm páginas que, sem serem clássicos, resistiriam à crítica do mais meticuloso purista? (Veríssimo apud Zilberman e Lajolo, I988, pp. 27I-2).

Como se vê, Leitura manuscripta corresponde aos anseios do crítico, com 45 autores entâo modernos tendo seus textos reproduzidos nessa obra: professores e escritores, sendo muitos deles poetas, romancistas, jornalistas, juristas, diplomatas, polí- 
ticos, entre outras profissóes, todos voltados a uma produção escrita para adultos. Desse modo, à exceção dos autores professores que escreviam livros didáticos voltados à infância - Arnaldo de Oliveira Barreto, Antonio Gomes Cardim, Barão de Macaúbas, Hilário Ribeiro, Romão Puiggari e Ramon Rocca Dordal - e que têm textos reproduzidos em Leitura manuscripta, os outros não têm em vista a especificidade da infância, mas são autores renomados, sobretudo representantes dos movimentos literários em voga e atuantes em diversas esferas da sociedade brasileira, como intelectuais, entre os quais, destacam-se: Álvares de Azevedo, Castro Alves, Escragnole Taunay, José Bonifácio, Gonçalves Dias, Fagundes Varela, Machado de Assis, Manuel Antonio de Almeida, Pedro Dinis, Raimundo Corrêa e Vicente de Carvalho.

É importante ressaltar que, no início do século XX, quando veio a lume a primeira edição de Leitura manuscripta, a produçáo literária para crianças era, em geral, composta por traduçôes e adaptaçóes (Lajolo e Zilberman, I99I), não havendo um número muito expressivo de autores que se ocupassem de escrever diretamente para a criança. Isso parece justificar a presença de autores voltados ao público adulto nas páginas do livro. E foi na relação com a escola e o ensino de leitura e escrita que a literatura infantil brasileira começou a tomar corpo e pôde, gradativamente, tornar-se um gênero autônomo. ${ }^{\text {I2 }}$ Assim, a partir da compreensão da infância como parte diferenciada da vida humana e do valor formativo do livro e da leitura, os autores passaram a se ocupar da especificidade da produção escrita diretamente para a criança.

\footnotetext{
I2 A constituição da literatura infantil brasileira não se deu sem impasses ou problemas. Diversos estudos que traçam um histórico do gênero apontam para as relaçôes entre literatura e ensino como um problema de origem. Nessa direçâo, ver Lajolo (1982); Lajolo e Zilberman (I99I); Zilberman e Lajolo (1988).
} 
Ainda sobre os autores, é necessário questionar por que, à exceção de Suzanina Cornaz e da marqueza de Alorna, todos eram homens, cabendo reflexôes tanto sobre o lugar e o papel das mulheres no cenário literário e social como o das meninas na instituição escolar.

Quanto aos textos compilados, podem ser divididos em duas categorias: uma que corresponde a textos de caráter mais informativo e outra de caráter mais ficcional. No entanto, a maioria apresenta inflexóes entre uma e outra categorias, havendo apenas prevalência de uma natureza sobre a outra. Em uma tentativa de categorização, os textos informativos foram quantificados no quadro a seguir.

Quadro 3.3 Textos com caráter informativo no livro Leitura manuscripta: liçóes colligidas

Tipos de texto

Quantidade

\begin{tabular}{lc}
\hline Diálogos & 2 \\
\hline Biografias & 7 \\
\hline Narração & 7 \\
\hline Descrição & IO \\
\hline Máximas & 2 \\
\hline Total & $\mathbf{2 8}$ \\
\hline
\end{tabular}

Fonte: Informaçôes retiradas de Leitura manuscripta: lições colligidas e organizadas pela autora.

Os ficcionais, por sua vez, estão relacionados no quadro a seguir.

Quadro 3.4. Textos com caráter ficcional no livro Leitura manuscripta: liçōes colligidas

Tipos de texto

Quantidade

\begin{tabular}{ll}
\hline Poemas & I6 \\
\hline Carta & I \\
\hline Narração & 8 \\
\hline
\end{tabular}


Tipos de texto

Quantidade

\begin{tabular}{ll}
\hline Descrição poética & 3 \\
\hline Trecho de romance & I \\
\hline Fábulas adaptadas & 2 \\
\hline Fábulas em verso & 2 \\
\hline Fábulas em versos parafraseadas & I \\
\hline Narrativa épica & I \\
\hline Apólogo & 2 \\
\hline Total & 37 \\
\hline
\end{tabular}

Fonte: Informaçôes extraídas de Leitura manuscripta: liçôes colligidas e organizadas pela autora.

Observa-se, nos Quadros 3 e 4, que, em alguns casos, os mesmos tipos de textos oscilam entre uma categoria e outra, apenas prevalecendo a natureza, em uma espécie de hibridismo. Esse aspecto remete à característica fluida das origens de uma literatura especialmente voltada a crianças no Brasil, qual seja, a de proporcionar ensinamento útil por um meio agradável. Assim, informação e ficção permeiam os textos dirigidos ou adaptados para crianças, uma vez que grande parte deles - em especial no livro em análise - foi escrita e publicada para circular no âmbito escolar, conforme já apontado em relação à origem do gênero denominado literatura infantil e à sua estreita ligação com a escola.

Arroyo (1968) foi o primeiro estudioso a admitir essa vinculação histórica não como a causa dos males da literatura infantil, mas como constitutiva dela. ${ }^{13}$ Já Zilberman e Lajolo (1988) indicam que esse modo de conceber a literatura infantil associou-a aos problemas da escola. Seja um ponto de vista, seja outro, o importante é compreender que, desde os fins do século XIX, a literatura infantil brasileira apresentou os seguintes aspectos: foi produzida e criticada sobretudo por professores ou intelectuais engajados em projetos educacionais; associou o aspecto estético à formação

13. O estudo da contribuição de Leonardo Arroyo para a literatura infantil brasileira pode ser consultado em Assis (2016). 
de valores para as crianças, concebendo-as como seres a "vir a ser"; e submeteu-se ao processo de escolarização de aprendizagem da leitura e da escrita, ou seja, esteve vinculada à instituição escolar.

Além do aspecto híbrido, é notória a diversidade textual que compóe o livro Leitura manuscripta. Notam-se, no Quadro 3.3, cinco diferentes tipos de textos informativos e, no Quadro 3.4, dez diferentes tipos de textos de ficção.

Nesse contexto, compreende-se que o ensino da leitura manuscrita correspondia também a uma gama de textos com diferentes fins e que, por essa razão, pressupunham a aprendizagem de diferentes leituras, diferença que não se circunscreve apenas à diversidade das letras. Como já ressaltado, a presença de textos oriundos da literatura é uma grande novidade, caracterizando uma literatura manuscrita nas leituras para a infância brasileira, o que diferencia esse livro de outros paleógrafos, embora também se encontrem narrativas de fatos históricos, biografias, descriçóes objetivas, entre outros.

Desse modo, não se pode categorizar Leitura manuscripta como integrante do gênero literatura infantil, mas é possível, pelo esforço de ficcionalização da leitura voltada a crianças, levando-se em conta a prevalência de textos com essa natureza (28 informativos e 37 de ficção), conceber esse livro de leitura como representativo também da leitura recreativa, e não somente da leitura com caráter pedagógico, como, à primeira vista, pode-se compreender um livro de leitura. Tanto é assim que os 37 textos de ficção correspondem a gêneros cuja função estética ocupa o primeiro plano. Portanto, esses textos presentes em um livro de leitura escolar correspondem também ao que se considerava leitura auxiliar, cujo cerne consistia em emocionar, predominantemente, e não somente servir como leitura de classe, destinada ao ensino de conteúdo escolar, como se observa no texto "As duas mães", de Bulhão Pato (s.d, p. 30). 
Numa igreja se encontraram

Duas mães em certo dia,

Uma entrava: nesse instante,

Toda cheia de alegria.

Orgulhosa e triunfante,

Levava chegado ao peito,

Um filhinho a baptizar.

Outra, a infeliz que sabia,

Levava um filho também,

Oh! Mas essa pobre mãe

Levava o filho a enterrar!

Cruzaram-se a poucos passos

A que trazia nos braços

Cheio de vida e conforto,

O filho dos seus encantos,

E a triste lavada em prantos,

Que seguia o filho morto.

Trocaram ambas o olhar,

Nisso a mãe afortunada

Foi que rompeu a chorar,

Enquanto a desventurada,

Que o filho tinha perdido,

Oh! maravilhas do amor!

No meio da sua dor

Sorriu ao recém-nascido!

Dada a natureza dos textos que compóem esse livro de leitura, é possível afirmar que houve um esforço de levar a leitura pedagógica e recreativa para o ensino da leitura manuscrita, prevalecendo 
um caráter muito mais de formação de valores morais e pedagógicos do que de conteúdo escolar. Por essa razão, a ideia de levar ensinamento útil de modo agradável prevaleceu nos protocolos de leitura do texto, seja de seus autores, seja de seus editores, com a presença da literatura em letra manuscrita. É importante lembrar que, à época de circulação desse livro, muitas eram as obras de leitura que se voltavam para a tônica de ensinar conteúdo por meio dos livros escolares destinados ao ensino da leitura. Leitura manuscripta, ao contrário desse modelo, fundava-se em um projeto de formação da criança não por meio de conteúdo escolar, mas de propagação de valores emocionais, morais e patrióticos, subsumidos nos textos que o compunham, dado seu caráter ficcional, exercendo, pois, função ao mesmo tempo educativa e formativa.

\section{Consideraçóes finais}

Neste estudo, buscamos examinar os textos e autores presentes no livro Leitura manuscripta: liçóes colligidas a partir da percepção de que os livros de leitura podem ser considerados uma fonte profícua para a história da leitura e do leitor. Logo, essa análise revelou características que permitem compreender o que se oferecia às crianças para a leitura na escola brasileira na primeira metade do século XX:

I. Os autores eram modernos e renomados, sendo, em sua maioria, brasileiros, homens e contemporâneos à publicação do livro Leitura manuscripta, o que resultava em textos atuais, de qualidade e prestígio para a época;

2. A natureza híbrida dos textos, oscilando entre textos informativos e de ficção, imprimia diversidade textual ao livro, mas, sobretudo, denotava preocupação com a formação de uma leitura escolar também conformada pela leitura auxiliar;

3. A função dos textos era, portanto, tanto pedagógica como de recreação, porém, no primeiro caso, não era o conteúdo escolar 
o objetivo do livro, mas os valores emocionais, morais e patrióticos, o que se garantia também com os textos de ficção.

Assim, conclui-se que Leitura manuscripta: liçôes colligidas traz um projeto de formação da infância brasileira em situação escolar, rompendo com o suporte dos materiais de leitura e, ao mesmo tempo, propondo um modo de ler que formou gerações de leitores na escola brasileira, por mais de meio século.

Esse modelo de formação não era exclusivo do livro em análise, porém o exame de seus textos aponta para singularidades que caracterizaram o que se entendeu por muito tempo como um (bom) livro de leitura (manuscrita).

Nesse sentido, estudar livros de leitura pode ser um caminho para a compreensão do que se oferecia às crianças brasileiras como leitura na escola, ou seja, o que se projetava para sua formaçáo.

\section{Referências}

ACADEMIA. “Sílvio Romero”. Disponível em: http://www.academia.org.br/ academicos/silvio-romero/biografia.

. "José Veríssimo". Disponível em: http://www.academia.org.br/academicos/jose-verissimo/biografia.

ARROYO, Leonardo. Literatura infantil brasileira: ensaio de preliminares para sua história e suas fontes. São Paulo: Melhoramentos, 1968.

ASSIS, Vivianny Bessão. A contribuição de Leonardo Arroyo (1918-1985) para a história da literatura infantil brasileira (tese). Universidade Estadual Paulista, 2016.

BATISTA, Antônio Augusto Gomes. "Papéis velhos, manuscritos impressos: paleógrafos ou livros de leitura”. In ABREU, Márcia e SHCAPOCHNIK, Nelson (orgs.). Cultura letrada no Brasil: objetos e práticas. Campinas: Mercado de Letras/Associação de Leitura no Brasil; São Paulo: Fapesp, 2005, pp. 87-II6. 
. "Dos papéis velhos aos manuscritos impressos: paleógrafos ou livros de leitura manuscrita”. In BATISTA, Antônio Augusto Gomes e GALVÃO, Ana Maria de Oliveira. Livros escolares de leitura no Brasil: elementos para uma história. Campinas: Mercado de Letras, 2009, pp. I53-78.

BERNARDES, Vanessa Cuba. "Arnaldo de Oliveira Barreto (I869-I925): atuação e produção para o ensino da leitura”. In MORTATTI, Maria do Rosário Longo et al. (orgs.). Sujeitos da história do ensino de leitura e escrita no Brasil. São Paulo: Unesp, 2015, pp. 93-102.

BPR. Leitura manuscripta: liçóes colligidas. Rio de Janeiro: Livraria Francisco Alves, s.d.

CHARTIER, Roger. A história cultural: entre práticas e representaçôes. Trad. Maria Manuela Galhardo. Lisboa: Difel; Rio de Janeiro: Bertrand Brasil, I990. CORRÊA, Rosa Lydia Teixeira. "O livro escolar como fonte de pesquisa em história da educação". Caderno Cedes, Campinas, n. 52, pp. II-24, nov. 2000.

DARNTON, Robert. O beijo de Lamourette: midia, cultura e revolução. São Paulo: Companhia das Letras, 2010.

HALLEWELL, Laurence. O livro no Brasil: sua história. 2 ed. São Paulo: EDUSP, 2005 .

HANSEN, Patrícia. “Autores, editores, leitores. O que os livros cívicos para crianças da Primeira República dizem sobre eles?”. História, São Paulo, v. 30, n. 2, pp. 5I-80, ago./dez. $201 \mathrm{I}$.

LAJOLO, Marisa. Usos e abusos da literatura na escola: Bilac e a literatura escolar na República Velha. Rio de Janeiro: Globo, 1982.

e ZILBERMAN, Regina. Literatura infantil brasileira: história e histórias. 5 ed. São Paulo: Ática, I99I.

PASQUIM, Franciele Ruiz. "Ramon Roca Dordal (I854-I938) e Carlos Alberto Gomes Cardim (I875-1938)”. In MORTATTI, Maria do Rosário Longo et al. (orgs.). Sujeitos da história do ensino de leitura e escrita no Brasil. São Paulo: Unesp, 2015, pp. 77-92.

PATO, Bulhão. "As duas mães”. In BPR. Leitura manuscripta: liçóes colligidas. Rio de Janeiro: Livraria Francisco Alves, s.d. p. 30. 
PFROMM NETO, Samuel et al. O livro na educação. Rio de Janeiro: Primor/ INL, 1974 .

RAZZINI, Márcia de Paula Gregório. "O poder dos livros de leitura no início do século XX". In MORTATTI, Maria do Rosário Longo e FRADE, Isabel Cristina Alves da Silva (orgs.). História do ensino de leitura e escrita: métodos e material didático. São Paulo: Unesp; Marília: Oficina Universitária, 20I4, pp. 29I-3I3.

ROMERO, Sílvio. "O professor Carlos Jansen e as leituras das classes primárias”. In ZILBERMAN, Regina e LAJOLO, Marisa. Um Brasil para crianças: para conhecer a literatura infantil brasileira. 2 ed. São Paulo: Global, 1988.

SANTOS, Luana Grazielle dos. "Cartilha da infancia, de Thomaz Galhardo". In MORTATTI, Maria do Rosário Longo et al. (orgs.). Sujeitos da história do ensino de leitura e escrita no Brasil. São Paulo: Unesp, 2015, pp. 23-33.

SOARES, Magda. "Um olhar sobre o livro didático". Presença Pedagógica. Belo Horizonte, v. 2, n. I2, pp. 53-63, nov./dez. 1996.

. "O livro didático como fonte para a história da leitura e da formação do professor-leitor”. In MARINHO, Marildes (org.). Ler e navegar: espaços e percursos da leitura. Campinas: Mercado de Letras; Belo Horizonte: Ceale, 200I. (Coleção Leituras no Brasil.)

VERÍSSIMO, José. "A educação nacional”. In ZILBERMAN, Regina e LAJOLO, Marisa. Um Brasil para crianças: para conhecer a literatura infantil brasileira. 2 ed. São Paulo: Global, 1988. 